\title{
Update on acute kidney injury after cardiac surgery
}

\author{
Andrew Shaw, MB, FRCA, FCCM
}

Objectives: To review the current state of clinical practice and discuss recent advances in the diagnosis and man-
agement of acute kidney injury (AKI) in the context of cardiac surgery.

\begin{abstract}
Methods: A review of the published data pertaining to AKI in the setting of cardiac surgery and cardiothoracic surgical critical care medicine was conducted, and the relevant data were synthesized from appropriate interventional and observational study reports.
\end{abstract}

\begin{abstract}
Results: Significant advances have occurred in the diagnosis of AKI, and consensus has been reported on a system of diagnosis using the serum creatinine and urine output. New biomarkers of injury and function are available that are likely to improve the interval to diagnosis of AKI after cardiac surgery. The adverse effect on outcome of small changes in serum creatinine is appreciated. Novel prevention and rescue therapies are now entering phase I and II studies. Urinary alkalinization was effective in a phase II blinded clinical trial and is now the subject of a multicenter, double-blind, randomized clinical trial of cardiac surgery patients.
\end{abstract}

Conclusions: In 2011, the field of AKI could be emerging from a period of stagnation that has lasted more than 2 decades. The failure to translate successful animal model interventions to the clinic might have resulted from delays in diagnosis that might now be avoidable with the advent of novel diagnostic biomarkers. (J Thorac Cardiovasc Surg 2012;143:676-81)

Acute renal failure is now referred to as acute kidney injury (AKI) — a term used widely throughout nephrology and critical care medicine. It has been adopted to focus attention on the spectrum of the illness, ranging from a minor change in serum creatinine or a brief period of oliguria to acute tubular necrosis requiring renal replacement therapy (RRT). A widely agreed conceptual model of $\mathrm{AKI}^{1}$ has been published and is reproduced in Figure 1.

In the present report, recent studies of the epidemiology of AKI after cardiac surgery ${ }^{2}$ have been reviewed and the new consensus diagnostic systems of Risk, Injury, Failure, Loss, End-Stage Renal Disease (RIFLE) ${ }^{3}$ and Acute Kidney Injury Network (AKIN) are discussed. ${ }^{4}$ The novel biomarkers of both kidney injury and declining kidney function have also been reviewed and the existing and novel treatment strategies summarized. The present report is a summary of a presentation during the Critical Care Seminar held at the 2010 meeting of the American Association for Thoracic Surgery in Toronto, Ontario, Canada.

From the Department of Anesthesiology, Duke University Medical Center, Durham, NC.

Disclosures: Dr Shaw has served as a consultant for Abbott Laboratories and FAST Diagnostics; both companies make products used in the diagnosis of acute kidney injury. He is also a member of the medical advisory boards of NxStage Medical and Gambro, both of which manufacture systems for continuous renal replacement therapy.

Received for publication May 20, 2010; revisions received June 22, 2011; accepted for publication Aug 24, 2011

Address for reprints: Andrew Shaw, MB, FRCA, FCCM, Department of Anesthesiology, Duke University Medical Center, Durham, NC 27710 (E-mail: andrew.shaw @ duke.edu).

0022-5223/\$36.00

Copyright (c) 2012 by The American Association for Thoracic Surgery

doi: $10.1016 /$ j.jtcvs.2011.08.054

\section{EPIDEMIOLOGY OF CARDIAC-ASSOCIATED AKI}

We have known for years that cardiac surgery is an important risk factor for acute kidney injury. Reports from several groups have described the incidence and prognostic importance of cardiac surgery-associated AKI for clinical outcomes in adult ${ }^{2,5}$ and pediatric ${ }^{6}$ cardiac surgical patients, and these have been placed both in the context of the specific operation performed ${ }^{7}$ and the type of practice. It is now understood that the overall incidence of AKI after adult cardiac surgery is about $5 \%$ to $10 \%{ }^{7}$ and is highly dependent on pre-existing renal function and the complexity of the proposed surgery. ${ }^{8}$ Several clinical risk factors have been consistently reported, and these are summarized in Table 1. The importance of acquired comorbid disease is clear in AKI, but the role of genetic variation as a determinant of both risk and outcome is much less well defined. It is probable that a patient's DNA sequence variants have more of an effect on host repair and regeneration biology than on the risk of AKI per se. ${ }^{9}$

Swaminathan and colleagues ${ }^{5}$ recently reviewed the National Inpatient Sample database and reported that the incidence of AKI after cardiac surgery appears to have increased in recent years. They pointed out that the incidence of new dialysis has not changed (still about $1 \%$ overall); thus, the likely reason for this finding is a loosening of the diagnostic criteria such that the AKI label is now applied more readily to patients with lesser reductions in kidney function. The significance of this was noted first by Chertow and colleagues, ${ }^{10}$ who noted an adverse effect on outcome in patients with seemingly trivial increases in serum creatinine. The validation of the new RIFLE criteria of Bellomo and colleagues ${ }^{3}$ in more than 500,000 patients underscores 


\author{
Abbreviations and Acronyms \\ AKI = acute kidney injury \\ AKIN $=$ Acute Kidney Injury Network \\ KIM-1 = kidney injury molecule 1 \\ $\mathrm{NGAL}=$ neutrophil gelatinase-associated \\ lipocalin \\ RRT = renal replacement therapy \\ RIFLE $=$ Risk, Injury, Failure, Loss, End-Stage \\ Renal Disease
}

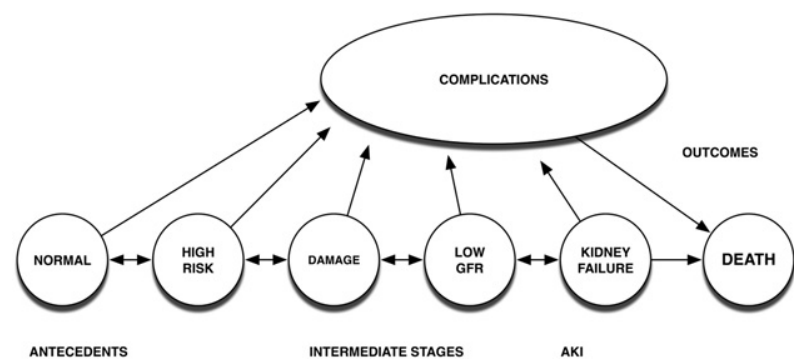

FIGURE 1. Conceptual model of acute kidney injury (AKI). GFR, Glomerular filtration rate. Reproduced from Murray and colleagues, ${ }^{1}$ with permission.

purposes, and in some intensive care units, their presence or absence is documented daily.

However, changes in serum creatinine occur late in the development of AKI-typically 48 hours after the initiating event (surgery in the case of cardiac surgery-associated AKI) ${ }^{13}$ An earlier diagnosis would surely assist with treatment and, even in the absence of demonstrably effective therapies, would at least permit avoidance of dehydration, excessive diuretic prescription, and other nephrotoxic interventions. Such timely diagnosis might be available shortly with the advent of novel biomarkers of both kidney injury and declining function. An exhaustive review was beyond the scope of the present report, but many excellent reviews are available on this topic. ${ }^{14,15}$ A brief summary of the biomarkers most likely to have the earliest impact is appropriate and follows below, with emphasis on neutrophil gelatinase-associated lipocalin (NGAL), kidney injury molecule 1 (KIM-1), and cystatin C.

\section{NEUTROPHIL GELATINASE-ASSOCIATED LIPOCALIN}

NGAL is a naturally occurring protein found in tissue and circulating in very low concentrations in the plasma. In cardiac surgery-associated AKI, it has been shown to be

TABLE 1. Clinical risk factors for cardiac surgery-associated acute kidney injury

\footnotetext{
Reduced preoperative renal function

Advanced age

African-American ethnicity

Increased body weight

Pulse pressure hypertension

Peripheral vascular disease

Diabetes mellitus (and metabolic syndrome)

Reduced left ventricular function

Anemia

Blood transfusion

Revision surgery

Aortic surgery

Poor intraoperative blood pressure control

Prolonged cardiopulmonary bypass
} in addition to the $50 \%$ increase option published in RIFLE. Either are suitable for both clinical and research 

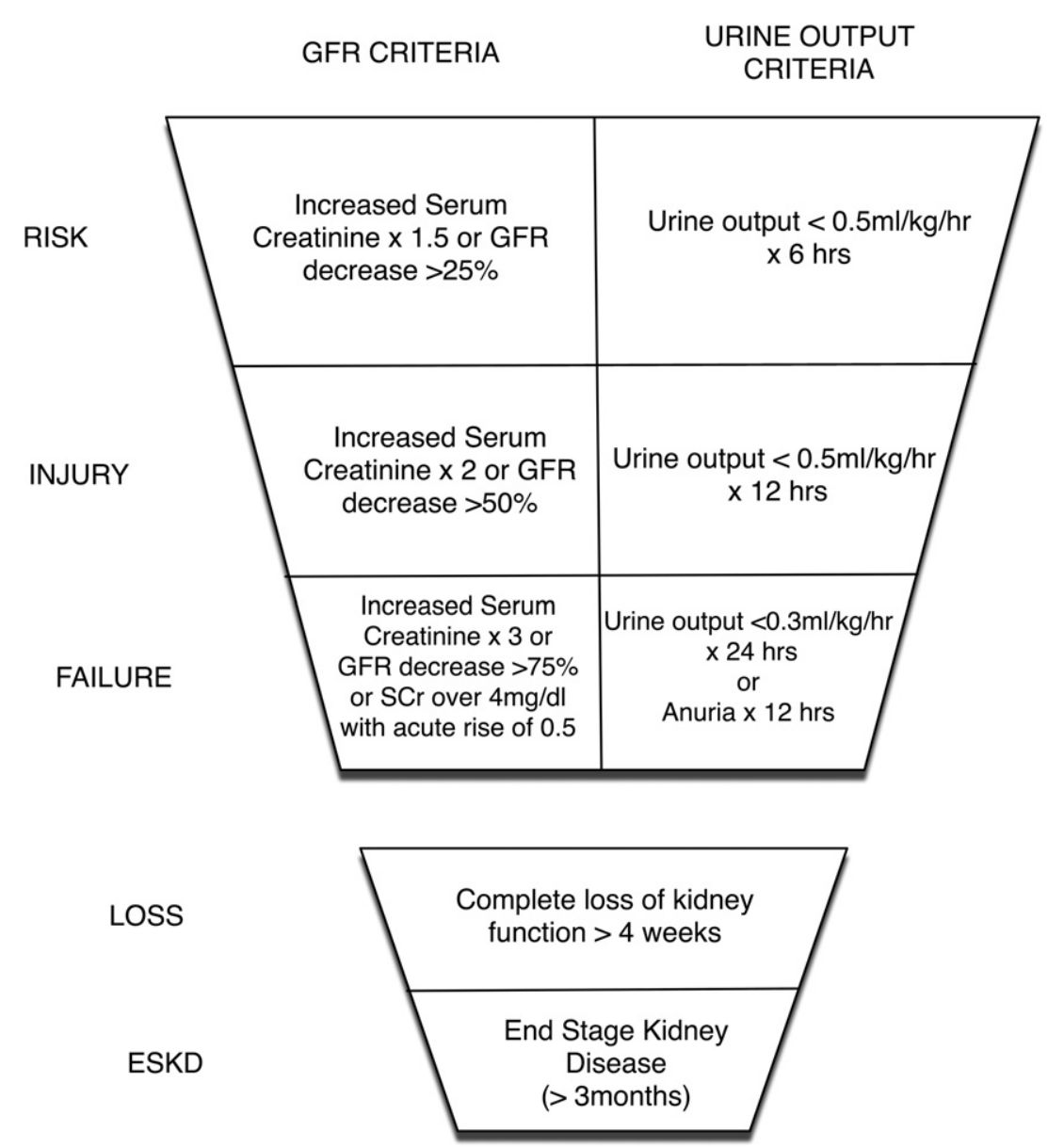

FIGURE 2. Risk, Injury, Failure, Loss, End-Stage Renal Disease (RIFLE) criteria. GFR, Glomerular filtration rate; $S C r$, serum creatinine; $E S K D$, end-stage kidney disease. Reproduced from Bellomo and colleagues, ${ }^{3}$ with permission.

elevated very early after surgery ( 2 hours after cardiopulmonary bypass in some reports), and both urinary and plasma assays are available. ${ }^{13}$ The tests are available for clinical use in Europe and will eventually also be available for use in North America. It is currently unclear which test provides the best diagnostic performance for AKI, but there is some suggestion that the combination of the two tests might be better than either alone. In general, urine is an attractive proximal fluid for kidney biomarker discovery and development, because tubular proteins leaking from damaged nephrons are concentrated, rather than diluted, as is the case in plasma. It is also probable that plasma NGAL is a closer reflection of systemic inflammation than the extent of renal injury inflicted. ${ }^{16}$ It is certain that once introduced into clinical practice, observational studies of this novel test will define its role in our diagnostic armory more clearly. In the meantime, it has great potential for use in intervention trials as a way of enriching the study population for randomization of putative interventions.

\section{KIDNEY INJURY MOLECULE 1}

KIM-1 is a transmembrane protein present in the renal proximal tubule whose expression is markedly upregulated in response to acute ischemia or exposure to nephrotoxins. Although several reports from noncardiac surgical patient populations have shown that KIM-1 appears to be a very

TABLE 2. AKIN criteria for diagnosis of AKI

\begin{tabular}{lll}
\hline Stage & \multicolumn{1}{c}{ Serum creatinine criteria } & \multicolumn{1}{c}{ Urine output criteria } \\
\hline 1 & Increase in serum creatinine of $\geq 0.3 \mathrm{mg} / \mathrm{dL}$ or increase to $\geq 150-200 \%$ & $<0.5 \mathrm{~mL} / \mathrm{kg} / \mathrm{hr}$ for $>6 \mathrm{hr}$ \\
& $(1.5-2$-fold) from baseline & $<0.5 \mathrm{~mL} / \mathrm{kg} / \mathrm{hr}$ for $>12 \mathrm{hr}$ \\
2 & Increase in serum creatinine to $>200-300 \%(>2-3$-fold) from baseline & $<0.3 \mathrm{~mL} / \mathrm{kg} / \mathrm{hr}$ for $24 \mathrm{hr}$ or anuria for $12 \mathrm{hr}$ \\
3 & Increase in serum creatinine to $>300 \%(>3$-fold) from baseline, serum & \\
& creatinine of $\geq 4.0 \mathrm{mg} / \mathrm{dL}$, with acute increase of $\geq 0.5 \mathrm{mg} / \mathrm{dL}$, or any dialysis & \\
\hline
\end{tabular}

AKI, Acute kidney injury; AKIN, Acute Kidney Injury Network. 
sensitive indicator of AKI, ${ }^{17}$ fewer cardiac surgery studies have been published. In one study of 103 adult patients undergoing cardiopulmonary bypass, the KIM-1 levels were significantly increased at both 2 and 24 hours after surgery in patients who subsequently developed AKI. ${ }^{18}$ In a recent review, KIM-1 was found to be a useful diagnostic assay for AKI after cardiac surgery but was less sensitive for predicting the need for dialysis or death. ${ }^{19}$

\section{CYSTATIN C}

Cystatin C is a "housekeeping" protein that is produced continuously by all nucleated cells. Because it is freely filtered at the glomerulus, is completely reabsorbed by the proximal convoluted tubule, and is not secreted, it has qualities that make it suitable for measuring the glomerular filtration rate. ${ }^{20}$ Compared with serum creatinine, it is less affected by age, gender, and body weight. In one prospective study, cystatin $\mathrm{C}$ and NGAL were measured in both the plasma and urine of 72 adults undergoing cardiac surgery. ${ }^{21}$ Within the first 6 hours, neither of the plasma assays for cystatin C or NGAL were predictive of AKI; however, the urinary values of both were elevated, suggesting that at least for these two candidate biomarkers, the urinary test might be superior to the plasma assay for the early detection of AKI.

\section{PREVENTION AND TREATMENT OF AKI Hydration}

It is known that adequate hydration reduces the risk that a patient will develop AKI. ${ }^{22}$ Typically, in postoperative cardiac surgery patients, the problem is that of too much extracellular fluid rather than too little, such that dehydration is less of a problem. Hypovolemia, however, is a different issue and requires aggressive correction if end-organ perfusion (and thus function) is to be preserved. Although in normal volunteers, the kidney has been shown to autoregulate its blood flow within a mean arterial pressure range of 60 to $120 \mathrm{~mm} \mathrm{Hg}$, it is not known whether this is also the case in patients who have recently been exposed to a period of hypothermic, nonpulsatile perfusion. However, the benefits of maintaining a cardiac index greater than $21 \cdot \mathrm{min}^{-1} \cdot \mathrm{m}^{-2}$ in the immediate postoperative period are widely appreciated in cardiac surgical intensive care units, ${ }^{23}$ and uncorrected gross hypovolemia is thus uncommon.

\section{Fluid Type}

There has recently been a suggestion that synthetic colloids based on starches might be nephrotoxic. ${ }^{24}$ It is important to realize, however, that that study used a second-generation starch product in an unbalanced crystalloid carrier. Therefore, these data are not generalizable to contemporary North American practice. It is clear that stroke volume optimization in high-risk general surgery patients reduces the length of stay, ${ }^{25}$ and data have suggested this might also be the case in heart surgery. ${ }^{26}$

\section{Blood Transfusion}

Bleeding and blood transfusion are central issues in cardiac surgical medicine and can account for up to $50 \%$ of the blood products prescribed and delivered in some institutions. It is known that anemia is a risk factor for AKI; however, so is the transfusion of stored blood. ${ }^{27}$ Whether the adverse effects of transfused stored blood that were reported in studies using nonleucodepleted blood ${ }^{28}$ will be reproduced in studies using leucodepleted blood is unclear. Antifibrinolytics have been associated with the development of $\mathrm{AKI}^{29}$ and also with the absence of increased risk. ${ }^{30}$ The currently available antifibrinolytic drugs appear not to carry any extra risk of AKI.

\section{Dopamine Agonists}

Decades of experience have shown that in low doses, dopamine is clearly a useful drug for weaning patients from epinephrine infusions and generally "toning up" the postcardiotomy circulation. It is also clear from the published data (a meta-analysis of 61 randomized "low-dose" $[<5$ $\mu \mathrm{g} / \mathrm{kg} / \mathrm{min}$ ] dopamine renoprotection trials, including 3359 patients, concluded no benefit was present in terms of mortality or dialysis ${ }^{31}$ ) that low-dose dopamine is not beneficial when given solely for a renal indication. It is true this drug does have natriuretic and diuretic properties, but these should not be confused with renal protection. Fenoldopam (a specific $\mathrm{DA}_{1}$ agonist) has a body of data ${ }^{32}$ supporting its use for improving renal blood flow and decreasing the incidence of AKI; however, it remains a boutique therapy used by enthusiasts only, for reasons that remain unclear. Compared with dopamine, in particular, fenoldopam appears to cause less atrial fibrillation. ${ }^{33}$

\section{Diuretics}

Almost all cardiac surgery patients receive loop diuretics at some point in their hospitalization and are often also receiving these drugs chronically. Rather than studying whether they should or should not be used, it would be more fruitful to discuss how they should be used. Data have suggested that infusions are associated with better outcomes than intermittent bolus administration, ${ }^{34}$ and ongoing trials are studying this exact question (S.M. Bagshaw, personal communication, March 2011). Mannitol is commonly added to cardiopulmonary bypass circuit prime, but no good data are available to support this practice.

\section{Natriuretic Peptides}

Perioperative infusions of human recombinant brain natriuretic peptide (nesiritide) have been shown to reduce AKI, shorten the hospital stay, and improve 6-month survival in a randomized study of 272 coronary bypass patients 
with impaired left ventricular function. ${ }^{35}$ However, the apparent enthusiasm for this seemingly good result should be balanced by the observation that in nonsurgical studies, brain natriuretic peptide appeared to worsen renal function in patients with heart failure, ${ }^{36}$ and a subsequent follow-up study has not been published to confirm this finding.

\section{Glycemic Control With Intravenous Insulin}

Reabsorption of tubular glucose is an active, energyconsuming process; thus, it is thought that reducing the metabolic burden in the tubules by reducing the concentration of urinary glucose might preferentially affect intrarenal oxygen flux. A randomized study of 1548 critically ill patients ( $63 \%$ of whom had undergone cardiac surgery) found a lower incidence of renal replacement therapy and improved survival with intensive (target glucose 80-110 $\mathrm{mg} / \mathrm{dL}$ ) compared with conventional (target 180-200 $\mathrm{mg} / \mathrm{dL}$ ) glycemic control. ${ }^{37}$ However, a large clinical trial in Australia and New Zealand subsequently questioned the benefit of tight glycemic control, suggesting no benefit compared with a less-aggressive glucose target. ${ }^{38}$

\section{Urinary Alkalinization}

It has been suggested that cardiac surgery-associated $\mathrm{AKI}$ is in large part a pigment nephropathy. ${ }^{39}$ Cold, nonpulsatile, extracorporeal circulation with passage through suction catheters, oxygenators, bubble traps, and filters is certainly a good recipe for hemolysis, and pink urine in the bladder catheter bag is indeed a familiar sight. Haase and colleagues ${ }^{40}$ conducted a preliminary trial of urinary alkalinization in cardiac surgery patients at high risk of AKI and showed that in patients randomized to a tonically equivalent dose of sodium bicarbonate (compared with sodium chloride), the incidence of AKI was less in the bicarbonate group. The urine of the bicarbonate patients was effectively alkalinized, which might have enhanced urinary excretion of free filtered hemoglobin. However, it is also possible that avoiding a chloride load also has beneficial effects on the kidney. A large follow-up trial is currently underway, the results of which are eagerly awaited.

\section{Renal Replacement Therapy}

In North America, RRT is generally a nephrologic business; however, in the rest of the world, continuous RRT (eg, hemofiltration) is largely an intensive care unit treatment. This disconnect has resulted because of nonclinical issues and represents an unfortunate development. Extracorporeal therapy will attract an ever increasing presence in the modern intensive care unit, as the extracorporeal philosophy leans more toward earlier, partial organ assist rather than later organ function replacement. As such, all those involved in intensive care management will require a working knowledge of partial cardiac assist, partial lung assist, partial liver assist, and partial kidney assist techniques. Although continuous venovenous hemofiltration is a physiologically simple concept (it is just like a glomerulus), it is important to consider the potential downside (ie, catheter placement complications, infection, bleeding, metabolic disturbance, fluid shifts) before its initiation. ${ }^{41}$ However, it is important that this technique becomes available to the wider intensive care unit community, just as ultrasonography has in recent years. In surgical practice, especially, understanding of the benefits of a zero-weight gain approach for perioperative medicine is increasing, ${ }^{42}$ and cardiac surgeons are well placed to lead the trend toward the earlier use of continuous venovenous hemofiltration in their volume-overloaded patients.

\section{CONCLUSIONS}

AKI is common in cardiac surgery patients, especially those with elevated preoperative serum creatinine who undergo on-pump surgery for something other than primary coronary artery bypass grafting. A new consensus definition, new biomarkers, new ideas about the pathophysiology, and new ideas about its prevention and treatment are available. This is an exciting time to be in perioperative nephrology, and our ability to identify an enriched at-risk population clinically and further stratify them with the use of new biomarkers makes cardiac surgery-associated AKI a particularly attractive domain for intervention trials.

\section{References}

1. Murray PT, Devarajan P, Levey AS, et al. A framework and key research questions in AKI diagnosis and staging in different environments. Clin J Am Soc Nephrol. 2008;3:864-8.

2. Ishani A, Nelson D, Clothier B, et al. The magnitude of acute serum creatinine increase after cardiac surgery and the risk of chronic kidney disease, progression of kidney disease, and death. Arch Intern Med. 2011;171:226-33.

3. Bellomo R, Ronco C, Kellum JA, Mehta RL, Palevsky P. Acute renal failureDefinition, outcome measures, animal models, fluid therapy and information technology needs: The Second International Consensus Conference of the Acute Dialysis Quality Initiative (ADQI) Group. Crit Care. 2004;8:R204-12.

4. Mehta RL, Kellum JA, Shah SV, et al. Acute Kidney Injury Network: Report of an initiative to improve outcomes in acute kidney injury. Crit Care. 2007;11:R31.

5. Swaminathan M, Shaw AD, Phillips-Bute BG, et al. Trends in acute renal failure associated with coronary artery bypass graft surgery in the United States. Crit Care Med. 2007;35:2286-91.

6. Dent CL, Ma Q, Dastrala S, et al. Plasma neutrophil gelatinase-associated lipocalin predicts acute kidney injury, morbidity and mortality after pediatric cardiac surgery: A prospective uncontrolled cohort study. Crit Care. 2007;11:R127.

7. Shaw A, Swaminathan M, Stafford-Smith M. Cardiac surgery-associated acute kidney injury: Putting together the pieces of the puzzle. Nephron Physiol. 2008;109:55-60.

8. Bellomo R, Auriemma S, Fabbri A, et al. The pathophysiology of cardiac surgery-associated acute kidney injury (CSA-AKI). Int J Artif Organs. 2008; 31:166-78.

9. Lu JC, Coca SG, Patel UD, Cantley L, Parikh CR. Searching for genes that matter in acute kidney injury: A systematic review. Clin J Am Soc Nephrol. 2009;4: 1020-31.

10. Chertow GM, Levy EM, Hammermeister KE, Grover F, Daley J. Independent association between acute renal failure and mortality following cardiac surgery. Am J Med. 1998;104:343-8.

11. Haase-Fielitz A, Bellomo R, Devarajan P, et al. Novel and conventional serum biomarkers predicting acute kidney injury in adult cardiac surgery-A prospective cohort study. Crit Care Med. 2009;37:553-60. 
12. Hudson C, Hudson J, Swaminathan M, Shaw A, Stafford-Smith M, Patel UD. Emerging concepts in acute kidney injury following cardiac surgery. Semin Cardiothorac Vasc Anesth. 2008;12:320-30.

13. Mishra J, Dent C, Tarabishi R, et al. Neutrophil gelatinase-associated lipocalin (NGAL) as a biomarker for acute renal injury after cardiac surgery. Lancet. 2005;365:1231-8.

14. Parikh CR, Devarajan P. New biomarkers of acute kidney injury. Crit Care Med. 2008;36:S159-65.

15. Ricci Z, Cruz DN, Ronco C. Classification and staging of acute kidney injury: Beyond the RIFLE and AKIN criteria. Nat Rev Nephrol. 2011;7:201-8.

16. Martensson J, Bell M, Oldner A, Xu S, Venge P, Martling CR. Neutrophil gelatinase-associated lipocalin in adult septic patients with and without acute kidney injury. Intensive Care Med. 2010;36:1333-40.

17. Ichimura T, Hung CC, Yang SA, Stevens JL, Bonventre JV. Kidney injury molecule-1: A tissue and urinary biomarker for nephrotoxicant-induced renal injury. Am J Physiol Renal Physiol. 2004;286:F552-63.

18. Liangos O, Tighiouart H, Perianayagam MC, et al. Comparative analysis of urinary biomarkers for early detection of acute kidney injury following cardiopulmonary bypass. Biomarkers. 2009;14:423-31.

19. Huang Y, Don-Wauchope AC. The clinical utility of kidney injury molecule 1 in the prediction, diagnosis and prognosis of acute kidney injury: A systematic review. Inflamm Allergy Drug Targets. 2011;10:260-71.

20. Dharnidharka VR, Kwon C, Stevens G. Serum cystatin C is superior to serum creatinine as a marker of kidney function: A meta-analysis. Am J Kidney Dis. 2002; 40:221-6.

21. Koyner JL, Bennett MR, Worcester EM, et al. Urinary cystatin C as an early biomarker of acute kidney injury following adult cardiothoracic surgery. Kidney Int. 2008;74:1059-69.

22. Rudnick MR, Kesselheim A, Goldfarb S. Contrast-induced nephropathy: How it develops, how to prevent it. Cleve Clin J Med. 2006;73:75-80, 83-7.

23. Westaby S, Balacumaraswami L, Sayeed R. Maximizing survival potential in very high risk cardiac surgery. Heart Fail Clin. 2007;3:159-80.

24. Brunkhorst FM, Engel C, Bloos F, et al. Intensive insulin therapy and pentastarch resuscitation in severe sepsis. N Engl J Med. 2008;358:125-39.

25. Wilson J, Davies S. Improving surgical outcomes: It is the destination not the journey. Crit Care. 2010;14:177.

26. Sander M, Spies CD, Berger K, et al. Prediction of volume response under openchest conditions during coronary artery bypass surgery. Crit Care. 2007;11:R121.

27. Stafford-Smith M, Newman MF. What effects do hemodilution and blood transfusion during cardiopulmonary bypass have on renal outcomes? Nat Clin Pract Nephrol. 2006;2:188-9.
28. Koch CG, Li L, Sessler DI, et al. Duration of red-cell storage and complication after cardiac surgery. $N$ Engl J Med. 2008;358:1229-39.

29. Shaw AD, Stafford-Smith M, White WD, et al. The effect of aprotinin on outcome after coronary-artery bypass grafting. N Engl J Med. 2008;358:784-93.

30. Furnary AP, Wu Y, Hiratzka LF, Grunkemeier GL, Page U Sr. Aprotinin does not increase the risk of renal failure in cardiac surgery patients. Circulation. 2007; 116:I127-33.

31. Friedrich JO, Adhikari N, Herridge MS, Beyene J. Meta-analysis: Low-dose dopamine increases urine output but does not prevent renal dysfunction or death Ann Intern Med. 2005;142:510-24.

32. Bove T, Landoni G, Calabro MG, et al. Renoprotective action of fenoldopam in high-risk patients undergoing cardiac surgery: A prospective, double-blind, randomized clinical trial. Circulation. 2005;111:3230-5.

33. Shorten GD. Fenoldopam: Potential clinical applications in heart surgery. Rev Esp Anestesiol Reanim. 2001;48:487-91.

34. Mehta RL, Pascual MT, Soroko S, Chertow GM, Group ftPICARDS. Diuretics, mortality, and nonrecovery of renal function in acute renal failure. JAMA. 2002; 288:2547-53.

35. Mentzer RMJ, Oz MC, Sladen RN, et al. Effects of perioperative nesiritide in patients with left ventricular dysfunction undergoing cardiac surgery: The NAPA Trial. J Am Coll Cardiol. 2007;49:716-26.

36. Witteles RM, Kao D, Christopherson D, et al. Impact of nesiritide on renal function in patients with acute decompensated heart failure and pre-existing renal dysfunction a randomized, double-blind, placebo-controlled clinical trial. J Am Coll Cardiol. 2007;50:1835-40.

37. van den Berghe G, Wouters P, Weekers F, et al. Intensive insulin therapy in critically ill patients. N Engl J Med. 2001;345:1359-67.

38. Finfer S, Chittock DR, Su SY, et al. Intensive versus conventional glucose contro in critically ill patients. N Engl J Med. 2009;360:1283-97.

39. Haase M, Haase-Fielitz A, Bagshaw SM, Ronco C, Bellomo R. Cardiopulmonary bypass-associated acute kidney injury: A pigment nephropathy? Contrib Neph rol. 2007;156:340-53.

40. Haase M, Haase-Fielitz A, Bellomo R, et al. Sodium bicarbonate to prevent in creases in serum creatinine after cardiac surgery: A pilot double-blind, randomized controlled trial. Crit Care Med. 2009;37:39-47.

41. Bapat V, Sabetai M, Roxburgh J, Young C, Venn G. Early and intensive continuous veno-venous hemofiltration for acute renal failure after cardiac surgery. In teract Cardiovasc Thorac Surg. 2004;3:426-30.

42. Bundgaard-Nielsen M, Secher NH, Kehlet H. "Liberal" vs. "restrictive" perioperative fluid therapy-A critical assessment of the evidence. Acta Anaesthesiol Scand. 2009;53:843-51. 